\title{
Acute Pancreatitis in Patients Living with HIV
}

Elfane Mouna*, Dollo Ibrahim, Ouladlahsen Ahd, Sodqi Mustapha, Marih Latifa, Chakib Abdelfettah and Marhoum Elfilali Kamal

Infectious Diseases Unit, Ibn Rochd UHC, Casablanca, Morocco

\begin{abstract}
Background: Acute pancreatitis in HIV positive patients remains a management challenge even with a Highly Active Antiretroviral Therapy (HAART) era.

Objective: Report the prevalence, clinical and radiological features of acute pancreatitis associated with HIV.

Patients and methods: Retrospective study conducted from January 1999 to June 2015 in HIV positive patients admitted with acute pancreatitis in the Infectious Disease Unit, Ibn Rochd, Casablanca. The Balthazar Grade score was used to assess radiological severity of the disease.

Results: During this period, 39 patients had an acute pancreatitis or an incidence of 0.6/1000 inhabitant/year. The mean age was 33.72 years (range: 18 to 48 years), mostly represented by females ( $68 \%$ to $32 \%$ male). The known risk factors included an alcohol abuse in 15 patients $(52 \%)$, a history of pancreatitis in two patients $(5 \%)$, cholecystitis in four patients $(14 \%)$, and intravenous drug abuse in two patients $(5 \%)$. Nineteen patients $(65 \%)$ were on HAART regimen and only nine patients $(31 \%)$ were receiving cotrimoxazole as prophylaxis. Twenty-two patients $(76 \%)$ were in stage C of CDC. Twenty-one (72\%) patients had a mean CD4 count below $200 / \mathrm{mm}^{3}$ and a HIV viral load above 1000 copies $/ \mathrm{ml}$ in seventy nineteen $(65 \%)$ patients. Pancreatitis was symptomatic in all cases. The median amylasemia level was $120 \mathrm{lU} / \mathrm{L}$, serum lipase $672.7 \mathrm{IU} / \mathrm{L}$ and $1,23 \mathrm{mg} / \mathrm{dl}$ triglycerides. All patients had an abnormal pancreas CT scan of which twelve (41\%) patients were in stage A of AP. The main causes found were drug toxicity of which 6 cases were due to stavudine, meglumine antimony in 3 cases, didanosine in 1 case, anti-tuberculous treatment in 1 case and opportunistic infections of which 4 cases were tuberculosis, 4 cases of cytomegalovirus disease and cryptosporidiosis in 2 cases respectively. The main complications were: shock in 9 cases, 2 cases of diabetes and pancreatic pseudocysts in 2 cases. The evolution was fatal in $45 \%$ of cases. The median duration for hospital course was 10 days (range $6-50$ days).
\end{abstract}

Conclusion: Acute pancreatitis is a serious condition in HIV-positive patients. Drug toxicity and opportunistic infections represented the most frequent causes.

Keywords: Acute pancreatitis; HIV infection; Antiretroviral therapy

\section{Introduction}

Pancreatitis is a well-described complication of human immunodeficiency virus (HIV), its combination antiretroviral therapy and immunosupression favoring development of infectious agents $[1,2]$. The pancreatic attacks are often represented by acute pancreatitis (AP) [3]. It represents a management problem because of its diverse modes of expression, multiplicity of causes and the high mortality rate. [4] Historically, this has been predominantly associated with the usage of nucleoside reverse transcriptase inhibitors (NRTIs) such as didanosine and stavudine [5,6], release of opportunistic agents (cytomegalovirus, cryptosporidiosis, Mycobacterium tuberculosis) or Kaposi disease. The advent of protease inhibitors in the late 1990s enabled a clear regression of incidence of these diseases [7]. However, AP remains common among patients living with HIV (PLHIV) due to the prevalence of comorbidities (alcohol, biliary disease, hypertriglyceridemia) and the toxicity of the drugs used in opportunistic diseases. Although quite common and serious, the AP is often tardily discovered due to the absence or latency of clinical manifestations [8,9]. Few studies have been conducted about pancreatic disorders in HIV infection. The present study is designed to determine primarily the incidence of AP in PLHIV. The secondary objective was to determine the contributing risk factors, biochemical markers, and radiological features of pancreatitis associated with HIV.

\section{Patients and Methods}

This was a retrospective study of all PLHIV hospitalized for AP in Infectious Diseases unit at University Hospital of Casablanca from
January 1999 to June 2015. AP was retained on clinical signs and the rise of serum lipase three times higher the upper limit of normal. We used Balthazar Grade scoring for assess severity of AP. The CD4 count was assessed at each episode of pancreatitis. The data was collected from the medical record. The parameters studied were demographic, clinical, biochemical, radiological, immunovirological and outcome of patients. Antiretroviral (ARV) treatment was taken in the 3 months preceding the diagnosis of the pancreatitis. Death was related to the AP when the patient died during the episode of the AP.

\section{Results}

During the study period, 39 episodes of acute pancreatitis (AP) were identified. The incidence was 0.6 per 1000 . The mean age of our study patients was 33,72 years (range, 18 to 48 years). Among 39 patients, twenty six $(68 \%)$ were female, thirty (32\%), male. Alcoholism was noted in 15 patients (52\%) and intravenous drug use in a two patient. Four patients (14\%) had a previous history of cholecystectomy prior to the admission and two patients had antecedent of pancreatitis. Nineteen patients (65\%)

*Corresponding author: Elfane Mouna, Infectious Diseases Unit, Ibn Rochd UHC, Casablanca, Morocco, Tel: 0660832362; E-mail: elfanemouna@gmail.com

Received June 28, 2016; Accepted July 09, 2016; Published July 16, 2016

Citation: Mouna E, Ibrahim D, Ahd O, Mustapha S, Latifa M, et al. (2016) Acute Pancreatitis in Patients Living with HIV. J AIDS Clin Res 7: 600. doi:10.4172/2155 6113.1000600

Copyright: (C) 2016 Mouna E, et al. This is an open-access article distributed under the terms of the Creative Commons Attribution License, which permits unrestricted use, distribution, and reproduction in any medium, provided the original author and source are credited. 
Citation: Mouna E, Ibrahim D, Ahd O, Mustapha S, Latifa M, et al. (2016) Acute Pancreatitis in Patients Living with HIV. J AIDS Clin Res 7: 600. doi:10.4172/2155-6113.1000600

Page 2 of 4

were receiving HAART therapy and nine (31\%) patients were receiving co-trimoxazole for Pneumocystitis jiroveci prophylaxis. We described the number of each NRTI, NNRTI, protease inhibitors received by our patient population at the time of AP in Table 1. Twenty-two patients (76\%) had stage C of HIV infection. Twenty-one (72\%) patients had a CD4 count less than 200 cells $/ \mathrm{mm}^{3}$ at the time of their episode of pancreatitis and nineteen (65\%) had a high viral load above 1000 copies/ $\mathrm{ml}$. AP had occurred at diagnosis of HIV infection in nine cases or patients in immunovirological failure in 11 cases. One patient was coinfected with the hepatitis B virus. The risk factors found were alcohol in $52 \%$ of cases, cholecystitis in $14 \%$ of cases, intravenous toxicomania in $4 \%$ of cases and the antecedent of pancreatitis in $4 \%$ of cases. AP was symptomatic in all cases. Among the cases of pancreatitis, the median amylase level was $120 \mathrm{U} / \mathrm{L}$ (normal 30-110), and the median lipase level was $672.7 \mathrm{U} / \mathrm{L}$ (normal 23-300). Triglyceride levels were $1.23 \mathrm{mg} / \mathrm{dl}$ (normal: $<1.5 \mathrm{mg} / \mathrm{dl}$ ). No patient had a significant hypertriglyceridemia. White blood cell count was $4500 / \mathrm{mm} 3$ (range, 600 to 15,800). Calcium and phosphate was normal in all cases. CT scan of the abdomen with intravenous contrast was performed in 28 patients (96.55\%) within 48 $\mathrm{h}$ of admission. We used the Balthazar grade to define the radiological changes in acute pancreatitis. A normal appearing pancreas (Grade A) was found in 12 patients (41\%); focal or diffuse enlargement of pancreas (Grade B); abnormalities in pancreatic gland with peripancreatic inflammation (Grade C); fluid collection in single location (Grade D) was found in seven patients (19\%) respectively; multiple fluid collections was noticed in four patients (11\%). Figure 1 is an image from cut of the

\begin{tabular}{|c|c|}
\hline ARV treatment (n: 19) & $\begin{array}{c}\text { Number of } \\
\text { patients }\end{array}$ \\
\hline Nucleoside Inhibitor of Reverse Transcriptase (NIRT) & \\
\hline Lamivudine & 16 \\
\hline Zidovudine & 8 \\
\hline Stavudine & 6 \\
\hline Tenofovir & 3 \\
\hline Emtricitabine & 3 \\
\hline Didanosine & 1 \\
\hline Non-Nucleoside Inhibitor of Reverse-Transcriptase (INNTI) & \\
\hline Efavirenz & 13 \\
\hline Protease Inhibitor & \\
\hline Lopinavir & 6 \\
\hline Ritonavir & 6 \\
\hline Table $1: A R V$ thep
\end{tabular}

Table 1: ARV therapy received by patients at the time of PA.

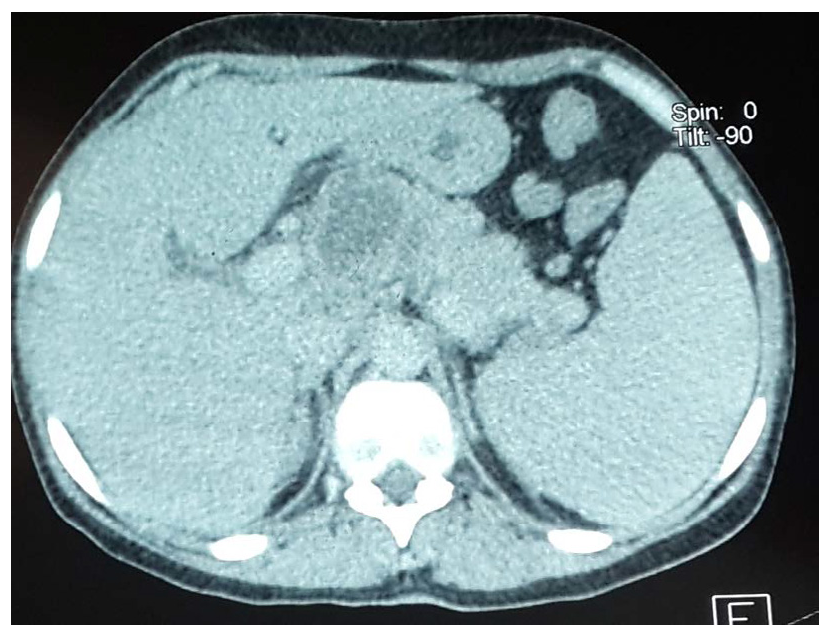

Figure 1: Scannographic image of stage $D$ acute pancreatitis.

\begin{tabular}{|l|c|c|}
\hline \multicolumn{1}{|c|}{ Causes } & Number & Percentage \\
\hline Drugs & 11 & 38 \\
\hline Stavudine & 6 & \\
\hline Antimoine de meglumine & 3 & \\
\hline Didanosine & 1 & \\
\hline Anti-tuberculous treatment & 1 & $\mathbf{3 5}$ \\
\hline Opportunistic Infection & $\mathbf{1 0}$ & \\
\hline Tuberculosis & 4 & \\
\hline Cytomegalovirus disease & 4 & $\mathbf{1 4}$ \\
\hline Cryptosporidiose & 2 & $\mathbf{7}$ \\
\hline Cholelithiasis & 4 & $\mathbf{3}$ \\
\hline Pancreatic tumor & 2 & $\mathbf{3}$ \\
\hline Alcohol & 1 & \\
\hline Indeterminate & 1 & \\
\hline
\end{tabular}

Table 2: Causes of acute pancreatitis.

CT scan of stage D acute pancreatitis in a 39 year old female. Drug was the cause of $12(38 \%)$ cases of AP. ARV treatment was responsible in seven cases (stavudine in 6 cases, didanosine in one case), antimony of meglumine in three cases and anti-bacillary treatment was the cause of two cases. Opportunistic infections were responsible for 35\% of cases. Those that were retained were tuberculosis ( 4 cases), cytomegalovirus infection ( 4 cases) and cryptosporidiosis (2 cases). Cholelithiasis was incriminated in four cases. Alcoholism, adenoma of the pancreas, malignant non-Hodgkin lymphoma were origine of one case each, while in one case, the etiology was unknown. Table 2 shows the distribution of etiologies of AP. The main complications observed were shock (10 cases), diabetes ( 2 cases) and pancreatic pseudocysts ( 2 cases). Thirteen deaths were attributable to the occurrence of severe AP.

\section{Discussion}

Although the annual incidence of AP in the general population is relatively low, estimated 17 to 30 cases per 100000 inhabitants [10], it is extremely variable during HIV infection and seems more frequent than the general population $[11,12]$. The incidence in our study ( 0.6 per 1,000 patients/year) was low compared to those reported in other studies. Phan et al had found an incidence of 6.7 cases per 1000 patients/year [13]. Whereas, the incidence was much higher than 140 cases per 1000 patients/year in the study of Dutta et al. [14]. The female sex has been implicated as a risk factor for pancreatitis in HIV/AIDS patients. We noted a female predominance of $68 \%$ of cases. This fact could be explained by the high prevalence of HIV in women compared to man in our country. Riedel et al. concluded that there is an association between female gender and acute pancreatitis [15]. However, other studies [3], did not adopt this hypothesis and it is the male sex which was considered as a risk factor [4]. In contrast with this, Euro SIDA group found there is no there is no sex difference in [16]. Chronic alcoholism was reported in half of our patients. This factor is known as a risk factor of pancreatitis but which is not specific for HIV infection. AP was symptomatic in all patients in our series. The clinical aspect of abdominal pain and vomiting was similar to that reported in the general population in $90 \%$ of cases. Other signs are frequently reported in PLHIV; diarrhea, hepatomegaly, fever, leukopenia, anemia or hypoalbuminemia and this in relation to their state of immunosuppression and malnutrition. [17]. The risk of pancreatitis is increased for the HIV/AIDS patients with lower CD4 cell counts. There is also evidence of an association with higher viral loads, suggesting that those with more advanced disease are at greater risk. Dragovic et al. also demonstrated an increased risk of pancreatitis with severe immunosuppression, particularly at the lowest CD4 counts, even after adjustment for HAART use. Consistent with data 
Citation: Mouna E, Ibrahim D, Ahd O, Mustapha S, Latifa M, et al. (2016) Acute Pancreatitis in Patients Living with HIV. J AIDS Clin Res 7: 600. doi:10.4172/2155-6113.1000600

Page 3 of 4

from other studies $[3,9,18,19]$, the AP had occurred in our study in patients with acute immunosuppression with CD4 count less than 200 cells $/ \mathrm{mm}^{3}$. Nadembèga affirms that the average rate of amylasemia is higher in patients with stage $\mathrm{C}$ than those in stage $\mathrm{A}$ and $\mathrm{B}$ (CDC classification). Dutta et al. found a correlation coefficient of less than 0.15 between amylasemia and CD 4 cell count [20]. In this part of study, Riedel had conducted a clinical trial that concluded that PLHIV with severe immunosuppression $\left(\mathrm{CD} 4<50\right.$ cells $/ \mathrm{mm}^{3}$ ) have a higher risk of pancreatitis [15]. Dragovic et al. had also reported an increased risk of AP in patients with severe immunosuppression, even after change of pancreatotoxic ARV [21]. These highly immunocompromised patients are prone to having pancreatic opportunistic infections (OI) [8]. Also, the prophylaxy of these OI by pentamidine and sulfamethoxazole trimethoprim is also associated with the occurrence of the AP [22]. During HIV infection, the distribution of causes of the AP is different from that of the general population. The drug causes are the most common followed by the OI and specific tumors with a lower incidence of bile causes [4]. The AP is a well-described complication of HIV as antiretroviral drugs. Moore et al. had reported a risk increase in patients receiving nucleoside reverse transcriptase inhibitors (NRTIs), especially didanosine [23]. Prolonged exposure to these molecules is associated with inhibition of DNA polymerase, the enzyme responsible for mitochondrial DNA replication, causing mitochondrial toxicity $[4,18,24]$. Under protease inhibitors especially in Lopinavir and Ritonavir, the AP is explained rather by the secondary hypertriglyceridemia, which is due to the decrease in peripheral clearance of triglycérides [25,26]. Cases of AP have been reported with zidovudine, corticosteroids, cyclins, acetaminophen, opioids. Furthermore, cotrimoxazole can to a lesser extent than pentamidine, cause pancreatitis [4,17]. In our series, seven cases of AP were associated with taking ARVs (stavudine and didanosine) and only nine patients received cotrimoxazole, suggesting that other risk factors contribute to the AP occurred in patients with a low rate CD4. The sodium antimony gluconate, used in the treatment of leishmaniasis can cause pancreatitis in case of use of high doses systemically. This is AP with favorable evolution and more frequently asymptomatic. However, severe pancreatitis has been reported in PLHIV treated with glucantime. [23] This drug was responsible for 3 cases of AP in our series whose evolution was fatal in one case. Opportunistic infections most often responsible for the AP are cytomegalovirus (CMV), Toxoplasma gondii, Cryptococcus neoformans, Candida, Mycobacterium tuberculosis, Mycobacterium and Cryptosporidium [4]. Infectious agents that we retained in our patients were CMV, cryptosporidium and mycobacterium tuberculosis. The severity of AP among PLHIV is identical to that of the general population. Recent analysis of causes of death in PLHIV found a prevalence of deaths linked to the AP in less than $2 \%$ [27]. This was close to that of our study (3\%). There are several limitations to our study, first of all, the study was done in a single management center of the HIV infection and the sample size was small. However, it yields useful information on risk factors and etiologies of AP.

\section{Conclusion}

The AP is an uncommon condition in HIV infection, but serious and with multifactorial origin. Alongside the classic causes described in the general population, there are specific pancreatic affections of HIV disease, deep immunosuppression, increased viral load, ARV treatment and (OI). Prevention of AP lies on early diagnosis of HIV infection, treatment education, aid with the withdrawal of alcohol consumption and the availability of alternative therapies.

\section{References}

1. Conférence de consensus: Pancréatite aiguë (2001) Gastroenterol. Clin Biol 25177-25192.

2. Dragovic $G$ (2013) Acute pancreatitis in HIVIAIDS patients: An issue of concern Asian Pac J Trop Biomed 3: 422-425.

3. Mocroft A, Ledergerber B, Katlama C, Kirk O, Reiss P, et al. (2003) Decline in the AIDS and death rates in the EuroSIDA study: An observational study. Lancet 362: 22-29.

4. Raza S, Naueen A, Chaudhrya NA, Jordan D, Rezai D, et al. (2013) To study the clinical, biochemical and radiological features of acute pancreatitis in HIV and AIDS. J Clin Med Res 5: 12-17.

5. Van Oosterhout JJ, Mallewa J, Kaunda S, Chagoma N, Njalale Y, et al. (2012) Stavudine toxicity in adult longer-term ART patients in Blantyre, Malawi. PLoS One 7: e 42029.

6. Sun HY, Chang SY, Sheng WH, Chen MY, Hsieh SM, et al. (2012) Incidence of acute pancreatitis in human immunodeficiency virus-positive patients with hypertriglyceridemia: Is it really high? Pancreas 41: 283-289.

7. Lugassy DM, Farmer BM, Nelson LS (2010) Metabolic and hepatobiliary side effects of antiretroviral therapy (ART). Emerg Med Clin North Am 28: 409-419.

8. Al Anazi AR (2009) Gastrointestinal opportunistic infections in human immunodeficiency virus disease. Saudi J Gastroenterol 15: 95-99.

9. Reisler RB, Murphy RL, Redfield RR, Parker RA (2005) Incidence of pancreatitis in HIV-1- infected individuals enrolled in 20 adult AIDS clinical trials group studies: lessons learned. J Acquir Immune Defic Syndr 39: 159-166.

10. Sah RP, Garg P, Saluja AK (2012) Pathogenic mechanisms of acute pancreatitis Curr Opin Gastroenterol 28: 507-515.

11. Leurquin-Sterk G, Schepers K, Delhaye M, Goldman S, Verset L, et al. (2011) Diffuse pancreatic lesion and al. mimicking autoimmune pancreatitis in an HIVinfected patient: Successful treatment by antiretroviral therapy. J Pancreas 12 : 477-481.

12. Manfredi R, Calza L (2008) HIV infection and the pancreas: Risk factors and potential management guidelines. Int J STD AIDS 19: 99-105.

13. Phan V, Thai S, Choun K, Lynen L, van Griensven J (2012) Incidence of treatment-limiting toxicity with stavudine-based antiretroviral therapy in Cambodia: A retrospective cohort study. PLoS One 7: e30647.

14. Dutta SK, Ting CD, Lai LL (1997) Study of prevalence, severity and etiological factors associated with acute pancreatitis in patients infected with human immunodeficiency virus. Am J Gastroenterol 92: 2044-2048.

15. Riedel DJ, Gebo KA, Moore RD, Lucas GM (2008) A ten year analysis of the incidence and risk factors for acute pancreatitis requiring hospitalization in an urban HIV clinical cohort. AIDS Patient Care STDS 22: 113-121.

16. Smith CJ, Olsen CH, Mocroft A, Viard JP, Staszewski S, et al. (2008) The role of antiretroviral therapy in the incidence of pancreatitis in HIV positive individuals in the Euro SIDA study. AIDS 22: 47-56.

17. Cappell MS, Marks M (1995) Acute pancreatitis in HIV-seropositive patients: A case control study of44 patients. Am J Med 98: 243-248.

18. Ueda T, Takeyama Y, Yasuda T, Shinzeki M, Sawa H, et al. (2006) Immunosuppression in patients with severe acute pancreatitis. J Gastroenterol 41: 779-784.

19. Moore RD, Keruly JC, Chaisson RE (2001) Incidence of pancreatitis in HIVinfected patients receiving nucleoside reverse transcriptase inhibitor drugs. AIDS 15: 617- 620.

20. Dutta SK, Ting CD, Lai LL (1997) Study of prevalence, severity and etiological factors associated with acute pancreatitis in patients infected with human immunodeficiency virus. Am. J. Gastroenterol 92: 2044-2052.

21. Dragovic G, Milic N, Jevtovic DJ (2005) Incidence of acute pancreatitis and nucleoside reverse transcriptase inhibitors usage. Int J STD AIDS 16: 427-429.

22. Kumar S, Schnadig VJ, MacGregor MG (1989) Fatal acute pancreatitis associated with pentamidine therapy. Am J Gastroenterol 84: 451-453.

23. Chebane L, Bagheri H, Hillaire-Buys, Géniaux H, Yahioui N, et al. (2015) Druginduced pancreatitis. A review of French spontaneous reports. Rev Med Int 36 573-578. 
Citation: Mouna E, Ibrahim D, Ahd O, Mustapha S, Latifa M, et al. (2016) Acute Pancreatitis in Patients Living with HIV. J AIDS Clin Res 7: 600. doi:10.4172/2155-6113.1000600

Page 4 of 4

24. 24. Fernandez-Montero JV, Eugenia E, Barreiro $P$, Labarga $P$, Soriano $V$ (2013) Anti-retroviral drug-related toxicities - clinical spectrum, prevention, and management. Expert Opin Drug Saf 125: 697-707

25. Périard D, Telenti A, Sudre P, Cheseaux JJ, Halfon P, et al. (1999) Atheroge-nic dyslipidemia in HIV-infected individuals treated with protease inhibitors. The Swiss HIV cohort study. Circulation 100: 700-705.
26. Saves M, Raffi F, Capeau J, Willy J, Jean Marie R, et al. (2002) Factors related to lipodystrophy and metabolic alterations in patients with HIV-infection receiving HAART. Clin Infect Dis 34: 1396-1405.

27. Gan I, May G, Raboud J, Tilley J, Enns R (2003) Pancreatitis in HIV infections: Predictors of severity. Am J Gastroenterol 98: 1278-1283. 